\title{
Comparison of Sensitivity and Specificity of ZN and Fluorescent Stain Microscopy with Culture as Gold Standard
}

\author{
Rekha Bansal ${ }^{1}$, Parveen Kumar Sharma ${ }^{2 *}$, Subhash Chand Jaryal' ${ }^{3}$, Puneet Kumar Gupta ${ }^{4}$, \\ Dinesh Kumar ${ }^{5}$
}

\begin{abstract}
${ }^{1}$ Department of Pulmonary Medicine, Dr. RP Government Medical College, Kangra at Tanda (HP), India
${ }^{2}$ Department of Pharmacology, SLBS Government Medical College, Mandi at Nerchowk (HP), India

${ }^{3}$ Department of Microbiology, SLBS Government Medical College, Mandi at Nerchowk (HP), India

${ }^{4}$ Department of Microbiology, All India Institute of Medical Sciences, Rishikesh, Uttarakhand, India

${ }^{5}$ Department of Community Medicine, Dr. RP Government Medical College, Kangra at Tanda (HP), India

Email: drdotrekha@gmail.com, ^drdotsharma@gmail.com,drscjaryal@gmail.com,drpuneetkumargupta@gmail.com,

dinesh9809@gmail.com
\end{abstract}

How to cite this paper: Bansal, R., Sharma, P.K., Jaryal, S.C., Gupta, P.K. and Kumar, D. (2017) Comparison of Sensitivity and Specificity of ZN and Fluorescent Stain Microscopy with Culture as Gold Standard. Journal of Tuberculosis Research, 5, 118128.

https://doi.org/10.4236/jtr.2017.52013

Received: May 20, 2017

Accepted: June 16, 2017

Published: June 19, 2017

Copyright $\odot 2017$ by authors and Scientific Research Publishing Inc. This work is licensed under the Creative Commons Attribution International License (CC BY 4.0).

http://creativecommons.org/licenses/by/4.0/

\begin{abstract}
Introduction: Reports indicate that fluorescent staining of smears increases sensitivity of direct microscopy; so ZN staining is being replaced with fluorescent microscopy in RNTCP in India. Chemical processing and sputum concentration may also improve sensitivity of microscopy. Objective: To compare the sensitivity and specificity of microscopy for AFB using $\mathrm{ZN}$ and fluorescent stains in direct and concentrated specimen with culture as gold standard. Methods: Morning sputum specimen of patients, suspected of having pulmonary tuberculosis, over a period of 6 months was subjected to direct microscopy using fluorescent stain; the same slide was over-stained with $\mathrm{ZN}$ stain. Same sputum sample was concentrated by Petroff s method and subjected to fluorescent microscopy followed by ZN microscopy and finally to culture for AFB. Results: Sensitivity of fluorescent stained concentrated sputum samples was maximum and of $\mathrm{ZN}$ stained unprocessed sputum samples was minimum. Specificity of three of the methods was equal at 0.96 but of $\mathrm{ZN}$ stained concentrated sputum smears was 0.97 . Sensitivity of total fluorescent stains was 0.85 (Specificity 0.96 ) and sensitivity of total ZN stained smears was 0.80 (Specificity 0.96). Discussion: We used same smear for fluorescent and ZN stains, so smear related variability is decreased. Blinding for microscopy was practically complete. Conclusion: The sensitivity of sputum microscopy for AFB can be increased by concentrating the sputum and using fluorescent microscopy. The specificity remains high in all the methods.
\end{abstract}




\section{Keywords}

Sensitivity and Specificity, Microscopy for AFB, ZN Staining, Fluorescent Stain, Concentration of Sputum

\section{Introduction}

Direct examination of sputum for acid-fast bacilli (AFB) by Ziehl-Neelsen (ZN) stained smears using conventional microscopy is a standard procedure in the diagnosis of pulmonary tuberculosis (TB) in high TB burden countries [1] [2] [3]. ZN stain has been preferred due to its relative simplicity, high specificity, low cost of reagents and simple microscope requirements [4]. Overall, over 30 mins may be needed for preparation and examination of each slide, thus limiting the number of slides that technicians can be expected to reliably examine daily ( 20 - 30) [2] [5]. Different factors that affect ZN sensitivity, smears and smear staining may be of poor quality, and it may not be possible to examine the recommended number of fields per slide due to fatigue and excessive workload [5]. These factors diminish the sensitivity of $\mathrm{ZN}$ microscopy and tuberculosis cases may be missed.

Fluorescence microscopy uses an acid-fast fluorochrome dye (eg. auramine $\mathrm{O}$ or auramine-rhodamine) with an intense light source such as a halogen or high-pressure mercury vapour lamp. The most commonly cited advantage of fluorescence microscopy is the possibility to scan a sputum smear at 250 magnifications rather than at 1000 magnifications, allowing a theoretical reduction of examination time of the same area to one sixteenth. Practically, the examination time is reduced about 10 -fold with fluorescence compared to bright-field microscopy using a four-fold different magnification (250 vs 1000) [6]. For this reason, fluorescent microscopy has been proposed by some experts for using in countries with a high prevalence of HIV infection [7] [8] and therefore ZN staining is being replaced with fluorescent microscopy in RNTCP in India. A potential shortcoming of fluorescence microscopy is the possibility of false-positive results because inorganic objects may incorporate fluorochrome dyes [9] [10].

Chemicals, such as sodium hydroxide $(\mathrm{NaOH})$ and a solution of $\mathrm{N}$-acetyl L-cysteine and sodium hydroxide ( $\mathrm{NaLC}-\mathrm{NaOH})$ to liquefy sputum, together with centrifugation, are widely used in modern laboratories [11] [12]. A recent review of studies using sodium hypochlorite $(\mathrm{NaOCl}$; bleach) to treat sputum followed by centrifugation found a significant increase in sensitivity compared with the direct smear method [13].

\section{Objectives}

The objective of this study was to compare the sensitivity and specificity of microscopy for AFB using ZN and fluorescent stains in direct and concentrated specimen with culture as gold standard in Dr. RP Government Medical College, Kangra at Tanda, Himachal Pradesh, India. 


\section{Study Population \& Methods}

The study was conducted after getting approval from Institutional Ethics Committee. All the patients fulfilling inclusion and exclusion criterion over a period of 6 months were enrolled in the study.

\section{Inclusion and exclusion criteria}

All the patients who were suspected of having pulmonary tuberculosis by the principal investigator based on history, clinical examination and $\mathrm{x}$-ray, requiring microscopy for AFB were included in the study after getting their written informed consent on proforma approved by Institutional Ethics Committee. Patients not willing to participate in the study were excluded.

\section{Study Procedure}

Early morning sputum specimen of all the patients was collected in sterile container. These specimens were subjected to direct microscopy using fluorescent stain (Auramin phenol) and then the same slide was over-stained with ZN stain.

The preparation of smear and staining was done as per RNTCP guidelines. The same sputum sample was concentrated by petroff's method using Sodium Hydroxide and then subjected to microscopy using fluorescent stain (Auramin phenol) followed by over-staining with ZN stain and finally to culture for AFB on Lowenstein Johnson medium.

The first direct fluorescent stain microscopy was done by a different technician and the other technician who did ZN over-staining of this direct sputum smear was not aware of the status of this smear. The status of the sputum collected from the patient was not known to the technician who did the concentration and fluorescent microscopy of the smears prepared from the concentrated sputum. For final ZN over-staining and reporting of the concentrated sputum smears a sufficient time gap of about 2 months was maintained so that the technician was unable to remember the status of the smears. Moreover the slides after $\mathrm{ZN}$ staining of the concentrated smears were kept by the investigator and provided to the technician randomly for reporting. Positive and negative control slides were included with each staining batch for internal quality control of the staining methods. $10 \%$ slides selected randomly were cross-checked by a microbiologist. The grading of sputum smears was done as per RNTCP guidelines for ZN staining [14] and a quantitation scale for acid-fast bacillus smears according to stain was used [15].

\section{Results}

During the study period of six months a total of 601 patients were suspected of having pulmonary tuberculosis based on history, clinical examination and chest x-ray and were included in the study. 163 (27.1\%) participants were females and 438 (72.9\%) were males. Mean ( $\pm 1 \mathrm{SD})$ age of the patients was $49.03( \pm 18.51)$ years and range was $4-89$ years. 65 percent of suspected tuberculosis and 73 percent of culture positive patients were underweight $(\mathrm{BMI}<18.5)$ and only 1 percent were obese (BMI 30 or more). (Figure $1 \&$ Figure 2)

\section{Clinical profile of study subjects}

Majority of the patients (54\%) presented with cough with or without other 


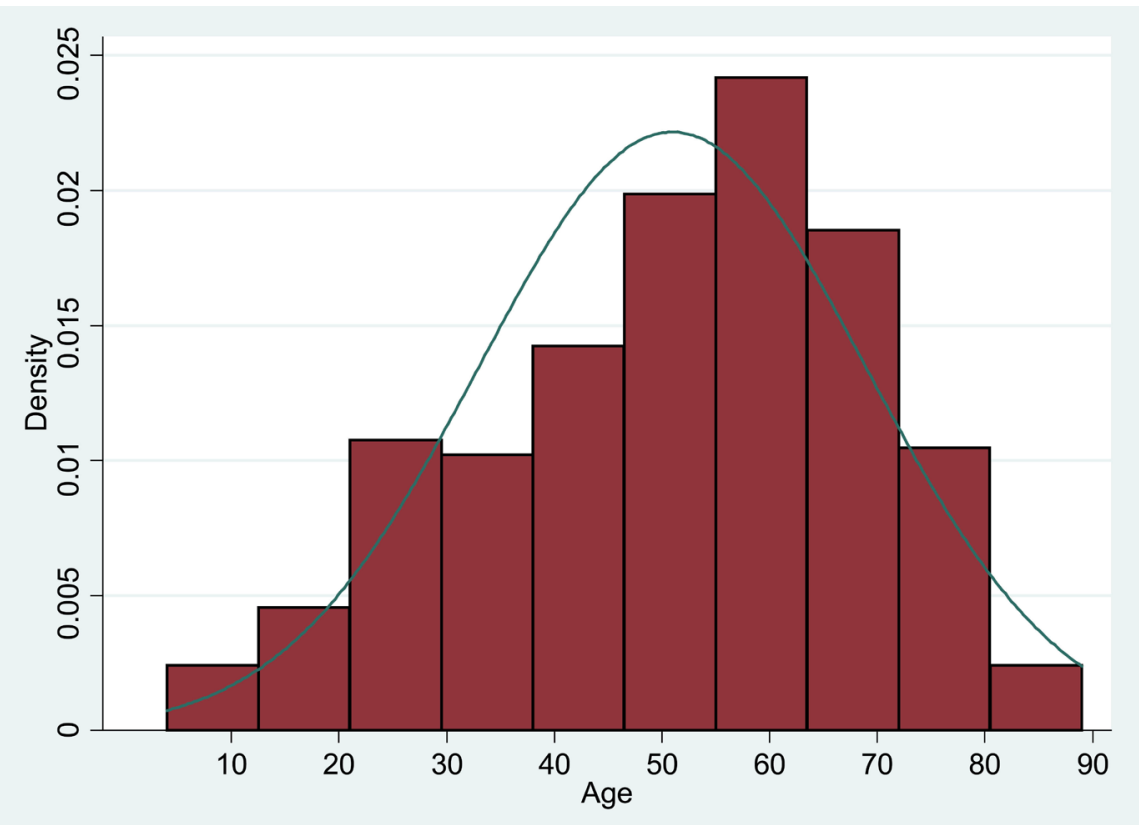

Figure 1. Age distribution of male study subjects.

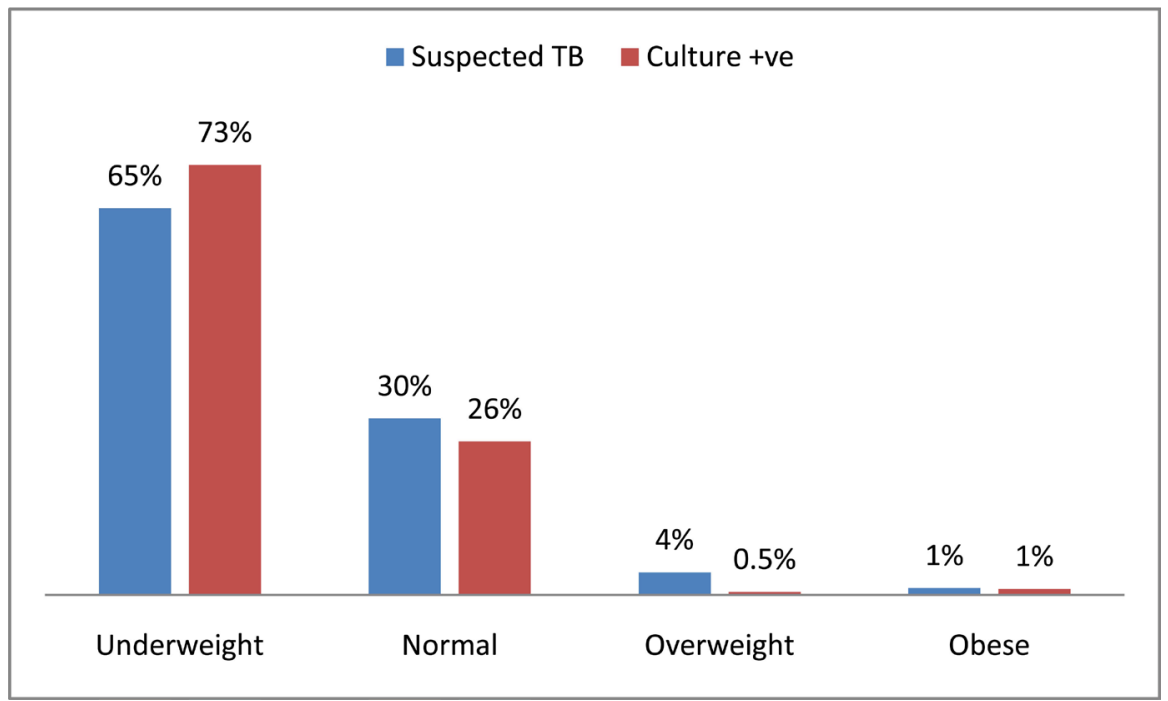

Figure 2. BMI of study subjects.

complaints followed by fever (28\%) with or without other complaints. The most common group of complaint was cough with fever in $18 \%$ patients. The median duration of presenting complaint was 20 days and range was 1 day to 3 years. (Figure 3)

Majority of the tuberculosis suspects and culture confirmed patients were having lesions in both lungs. $42 \%$ of those patients who had lesions in both lungs were culture positive, $35 \%$ of those with $\mathrm{x}$-ray lesions on left side were positive on culture and $32 \%$ of those with $\mathrm{x}$-ray lesions on right side were positive on culture.

Sputum profile of study subjects

All 601 suspected tuberculosis patients underwent direct and concentrated 
fluorescent microscopy followed by over-staining with $\mathrm{ZN}$ stain and finally culture for AFB. (Table 1)

Sputum smears were graded in $1+, 2+, 3+$ and scanty, an indication of the bacterial load in the sputum. (Tables 2-4)

Following graph (Figure 4) shows clusters of grades as proportion of total positive samples reported with that method.

When we combined unprocessed or direct fluorescent smears (601 smears) and processed or concentrated fluorescent stained smears (601 smears) then, a total of 402 out of 1202 smears (33.4\%) were positive for AFB. Similarly clubbing the data of direct ZN (601 smears) and Concentrated ZN stained smears (601 smears) 376 out of 1202 smears (31.3\%) were positive for AFB. Share of various

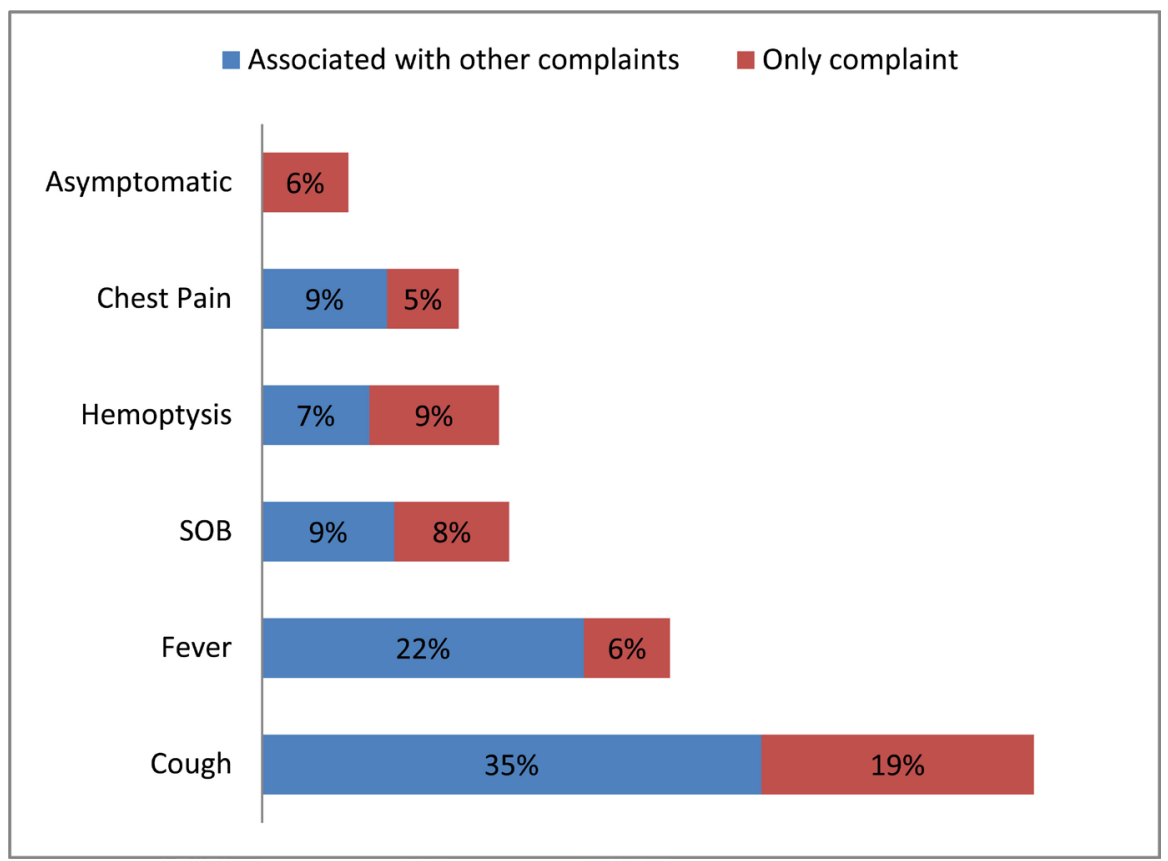

Figure 3. Presenting complaints in suspected tuberculosis subjects.

Table 1 . Sensitivity and Specificity of various sputum smears $(\mathrm{N}=601)$.

\begin{tabular}{lcccc}
\hline & $\begin{array}{c}\text { Unprocessed } \\
\text { Fluorescent Stain }\end{array}$ & $\begin{array}{c}\text { Unprocessed } \\
\text { ZN Stain }\end{array}$ & $\begin{array}{c}\text { Concentrated } \\
\text { Fluorescent Stain }\end{array}$ & $\begin{array}{c}\text { Concentrated } \\
\text { ZN Stain }\end{array}$ \\
\hline Sensitivity (95\% CI) & $0.81(0.75$ to 0.86$)$ & $0.79(0.72$ to 0.84$)$ & $0.89(0.83$ to 0.92$)$ & $0.80(0.74$ to 0.85$)$ \\
Specificity (95\% CI) & $0.96(0.93$ to 0.97$)$ & $0.96(0.93$ to 0.98$)$ & $0.96(0.94$ to 0.98$)$ & 0.97 (0.94 to 0.98) \\
\hline
\end{tabular}

Table 2. Percent of various grades in sputum smears using different staining methods (N $=601)$.

\begin{tabular}{cccccc}
\hline Sputum Status & $\mathbf{1 +}$ & $\mathbf{2 +}$ & $\mathbf{3 +}$ & Scanty & Negative \\
\hline Unprocessed Fluorescent Stain & $8.5 \%$ & $7.8 \%$ & $10.6 \%$ & $5.3 \%$ & $67.7 \%$ \\
Unprocessed ZN Stain & $10.6 \%$ & $7.7 \%$ & $8.8 \%$ & $4.2 \%$ & $68.7 \%$ \\
Concentrated Fluorescent Stain & $9.8 \%$ & $10.3 \%$ & $12.6 \%$ & $1.8 \%$ & $65.4 \%$ \\
Concentrated ZN Stain & $12.1 \%$ & $8.2 \%$ & $7.2 \%$ & $3.8 \%$ & $68.7 \%$ \\
\hline
\end{tabular}


Table 3. Cross tabulation of unprocessed fluorescent and unprocessed ZN stained smears.

\begin{tabular}{|c|c|c|c|c|c|c|c|}
\hline \multirow{2}{*}{ Unprocessed Fluorescent } & \multicolumn{6}{|c|}{ Unprocessed ZN } & \multirow{2}{*}{ Culture + ve } \\
\hline & Scanty & +1 & +2 & +3 & $\mathrm{Neg}$ & Total & \\
\hline Scanty & 12 & 6 & 1 & 2 & 11 & 32 & 28 \\
\hline+1 & 9 & 31 & 3 & 3 & 5 & 51 & 40 \\
\hline+2 & 1 & 17 & 24 & 4 & 1 & 47 & 46 \\
\hline+3 & 0 & 6 & 17 & 41 & 0 & 64 & 64 \\
\hline $\mathrm{Neg}$ & 3 & 4 & 1 & 3 & 396 & 407 & 41 \\
\hline Total & 25 & 64 & 46 & 53 & 413 & 601 & \\
\hline Culture + ve & 20 & 54 & 45 & 53 & 47 & & 219 \\
\hline \multicolumn{3}{|c|}{ Pearson $\mathrm{Chi}^{2}$ (16): 891.4789} & \multicolumn{3}{|c|}{ Pr: 0.0000} & & \\
\hline
\end{tabular}

Table 4. Cross tabulation of unprocessed fluorescent and concentrated fluorescent stained smears.

\begin{tabular}{|c|c|c|c|c|c|c|c|}
\hline \multirow{2}{*}{ Unprocessed Fluorescent } & \multicolumn{6}{|c|}{ Concentrated Fluorescent } & \multirow{2}{*}{ Culture + ve } \\
\hline & Scanty & +1 & +2 & +3 & $\mathrm{Neg}$ & Total & \\
\hline Scanty & 7 & 14 & 4 & 3 & 4 & 32 & 28 \\
\hline+1 & 1 & 16 & 25 & 5 & 4 & 51 & 40 \\
\hline+2 & 0 & 8 & 17 & 21 & 1 & 47 & 46 \\
\hline+3 & 0 & 10 & 13 & 41 & 0 & 64 & 64 \\
\hline Neg & 3 & 11 & 3 & 6 & 384 & 407 & 41 \\
\hline Total & 11 & 59 & 62 & 76 & 393 & 601 & \\
\hline Culture + ve & 11 & 52 & 57 & 74 & 25 & & 219 \\
\hline \multicolumn{3}{|c|}{ Pearson Chi (16): 684.3712} & \multicolumn{3}{|c|}{ Pr: 0.0000} & & \\
\hline
\end{tabular}

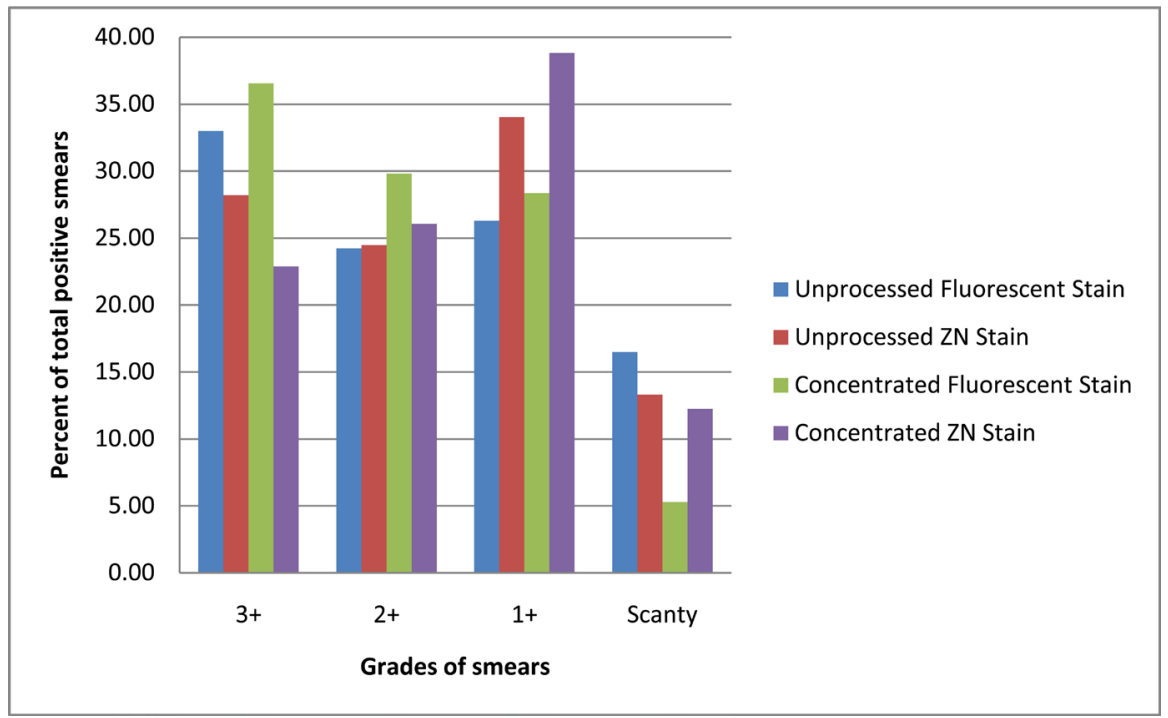

Figure 4. Sputum smears grading of study subjects. 


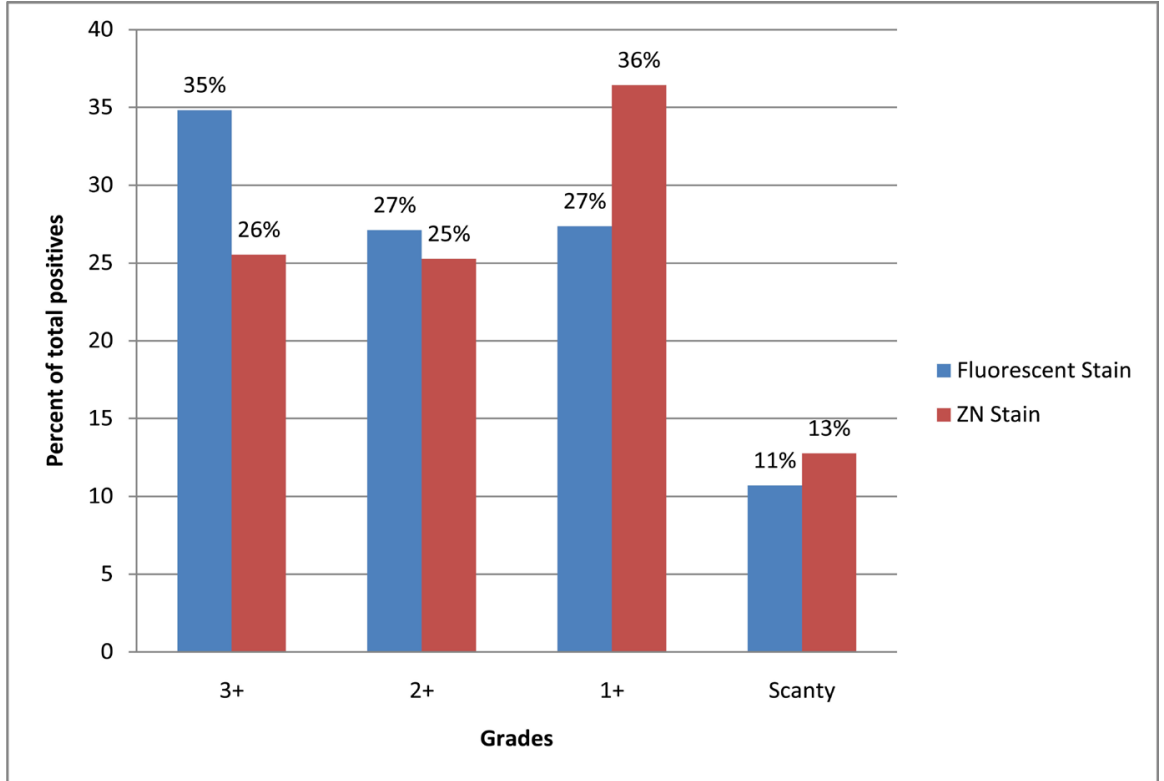

Figure 5. Comparison of grades of fluorescent and ZN stained sputum smears.

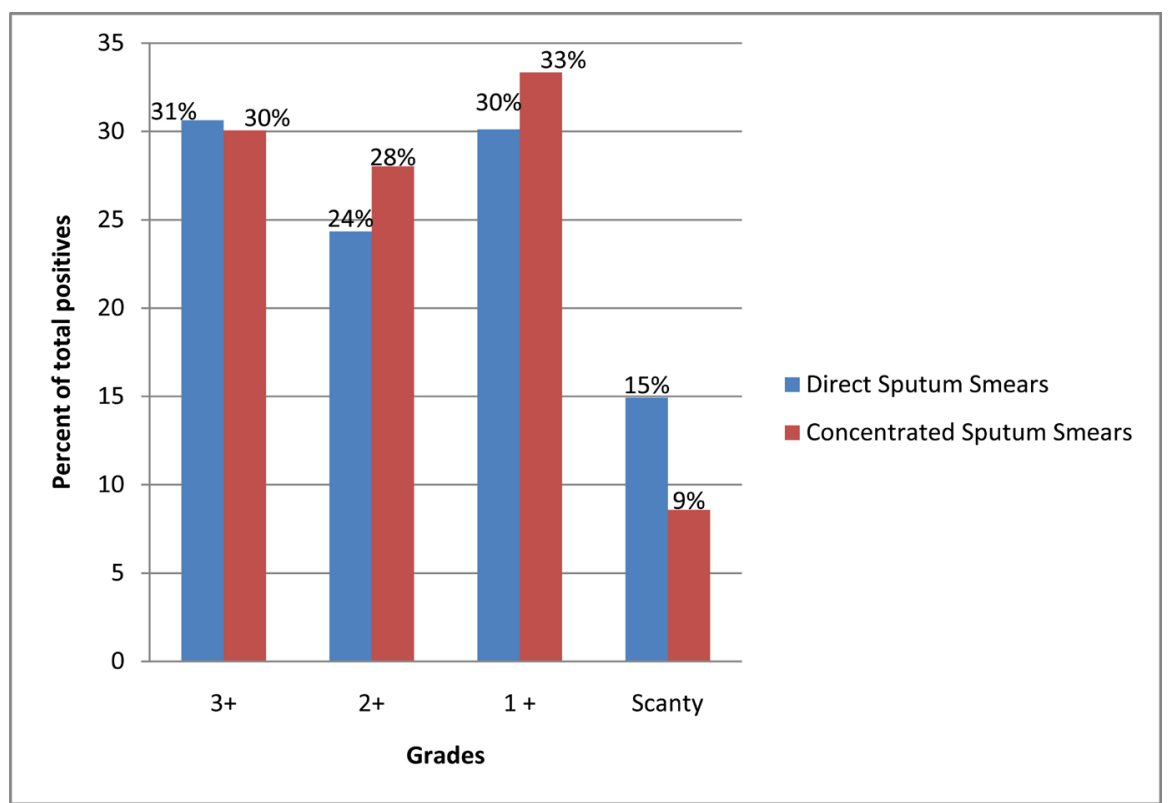

Figure 6. Comparison of grades of direct and concentrated sputum smears.

grades out of total positive smears is plotted. (Figure 5)

When we combined all unprocessed or direct smears (601 Direct Fluorescent and 601 Direct ZN smears), 382 of 1202 smears (32\%) were positive for AFB. Similarly clubbing the data of all concentrated sputum smears (601 Concentrated Fluorescent and 601 Concentrated ZN smears) 396 of 1202 smears (33\%) were positive for AFB. Share of various grades out of total positive smears is plotted. (Figure 6)

When we combined all smears that were reported using fluorescent stain $(\mathrm{N}=$ 1202; direct 601 and concentrated 601) and those which were reported using ZN stain method $(\mathrm{N}=1202$; direct 601 and concentrated 601$)$ the sensitivity of total 
fluorescent stains was 0.85 and the sensitivity of total $\mathrm{ZN}$ stained smears was 0.80 thus the difference in sensitivity was $5 \%$. The specificity of total fluorescent and total ZN stained smears was same 0.96 and there was no difference.

When we combined all smears prepared from unprocessed sputum $(\mathrm{N}=1202$; fluorescent stain 601 and $\mathrm{ZN}$ stain 601) and those prepared with concentrated sputum $(\mathrm{N}=1202$; fluorescent stain 601 and $\mathrm{ZN}$ stain 601$)$ the sensitivity of all unprocessed sputum smears was 0.80 and sensitivity of all concentrated sputum smears was 0.85 so, the difference in sensitivity was $5 \%$. The difference in specificity of total unprocessed and total concentrated sputum smears was only $1 \%$.

\section{Discussion}

Various factors influence the sensitivity and specificity of direct microscopy for AFB (Acid Fast Bacilli), like prevalence and severity of the disease, the quality of specimen collection, the number of mycobacteria present in the specimen, the method of processing (Direct or concentrated), the staining technique and the quality of the examination (Microscope operator expertise, time spent for smear examination) etc. [16] [17]. The reasons for huge variability in sensitivity and specificity in various studies are also multiple. Methodology is very important as the sensitivity would be different if different smears are prepared for staining with $\mathrm{ZN}$ and fluorescent stains. How many smears are used to decide the positivity for AFB? Whether gold standard is present? If so, what is the gold standard? If gold standard is culture then what is the quality of culture or how many cultures were contaminated? Whether blinding is complete? How many technicians are involved? What is the place of study? What is the composition of stain? What is the thickness of smear etc? In our study we tried to address most of these issues. We used the same smear for staining with both fluorescent and ZN stains, so smear related variability is decreased. The gold standard in our study is most reliable i.e. culture and only $0.5 \%$ of the cultures were contaminated. The study is conducted in the true working set up of the RNTCP and not in a research set up. The blinding for microscopy was practically complete as described in the methodology.

The sensitivity of Direct or unprocessed fluorescent, direct ZN, Concentrated fluorescent and Concentrated ZN methods in our study was 0.81, 0.79, 0.89 and 0.80 respectively. In a systemic review [18] of smear reports for AFB from all over the world the figures of sensitivity reported ranged from 0.52 to 0.97 for direct fluorescent microscopy, 0.32 to 0.94 for direct $\mathrm{ZN}$ microscopy method, 0.39 to 0.93 for concentrated fluorescent and 0.44 to 0.98 for concentrated $\mathrm{ZN} \mathrm{mi-}$ croscopy. So the figures in our study are on the higher side of the reported range. If we combine all the slides examined with fluorescent microscopy and all the slides examined with ZN stain method, we find that the sensitivity increases by $5 \%$ when fluorescent microscopy is used. This may be because an intense light source is used in fluorescent microscopy, visibility of the AFB is better and fatigue is also less compared to $\mathrm{ZN}$ stain.

The specificity of Direct Fluorescent, Direct ZN, Concentrated Fluorescent 
and Concentrated ZN smears is $0.96,0.96,0.96$ and 0.97 respectively. This is also on the higher side of the figures reported worldwide which range from 0.94 to 1.0 for direct fluorescent microscopy, 0.94 to 1.0 for direct $\mathrm{ZN}$ method, and 0.91 to 1.0 for Concentrated $\mathrm{ZN}$ [19]. If we combine all slides examined with fluorescent microscopy and all the slides examined with $\mathrm{ZN}$ staining, then we find that the specificity of fluorescent and ZN stain microscopy remains same.

There is an increase in sensitivity of $8 \%$ with concentration of sputum using fluorescent microscopy but when $\mathrm{ZN}$ stain method is used the increase in sensitivity is only 1\%. Data of Direct Fluorescent stain and Direct ZN stain is combined and compared with combined data of Fluorescent stain smears and ZN stain smears of concentrated sputum, we find the sensitivity of concentrated sputum smears is $5 \%$ more than unprocessed smears and specificity of concentrated sputum smears is $1 \%$ more than direct sputum smears.

In our study the sensitivity of concentrated $\mathrm{ZN}$ smear is very less compared to concentrated fluorescent smears and there is not much difference in the specificity of various methods. This may be because we did over-staining of fluorescent stained smears with $\mathrm{ZN}$ stain. In this method some of the bacteria may not re-stain and some might get washed away because of repeated washing and staining and so there may be an underreporting of sensitivity of $\mathrm{ZN}$ stain [17]. But if this is a real value then the strategy of referring the sputum found negative on Direct Fluorescent method for concentration microscopy method should be reviewed because in Microbiology Departments in India Fluorescent stain method is rarely available and so the reporting of concentrated sputum is done using $\mathrm{ZN}$ stain. It is suggested by some investigators that with decreasing number of bacilli the correspondence with culture of both fluorescent and bright field microscopy decreases. The correspondence of low scanty results on fluorescent microscopy was poorer compared to low scanty results on $\mathrm{ZN}$ staining. The fact is substantiated in our study where 28 out of $32(87.5 \%)$ scanty results on direct fluorescent microscopy and 20 out of 25 (80\%) scanty results on direct $\mathrm{ZN}$ staining were culture positive though this correspondence increased when sputum was concentrated and all 11 scanty results on Concentrated Fluorescent and 22 out of 23 (96\%) scanty results on Concentrated ZN staining were culture positive. Because in our study there does not appear to be any difference in the correspondence of fluorescent and $\mathrm{ZN}$ staining, this appears to be a better practice to get the culture done in cases of scanty sputum results.

\section{Conclusion}

The sensitivity of testing direct sputum smears for AFB using fluorescent stains is $2 \%$ more compared to $\mathrm{ZN}$ stain but specificity of both tests remains almost same. Concentrating the sputum increases the sensitivity of detecting AFB using fluorescent stain by $8 \%$ without affecting specificity.

\section{Statistical Analysis}

The sensitivity of the methods was calculated using the formula "True positive 
i.e. culture positive divided by total test positive smears" and specificity was calculated as "True negative i.e. culture negative divided by total test negative smears". Percentage and proportions were calculated using Microsoft Excel.

\section{Acknowledgements}

The project was funded by Central TB Division, Ministry of Health, Government of India through National Health Mission. Authors recognize the work of Mr. Anil Kumar, Laboratory Technician who helped in processing the samples.

\section{References}

[1] Tuberculosis Division International Union against Tuberculosis and Lung Disease (2005) Tuberculosis Bacteriology_Priorities and Indications in High Prevalence Countries: Position of the Technical Staff of the Tuberculosis Division of the International Union against Tuberculosis and Lung Disease. International Journal of Tuberculosis and Lung Disease, 9, 355-361.

[2] World Health Organization (1998) WHO Laboratory Services in Tuberculosis Control. Part II: Microscopy. WHO/TB/98.258. WHO, Geneva, 30-32.

[3] Foulds, J. and O'Brien, R. (1998) New Tools for the Diagnosis of Tuberculosis: The Perspective of Developing Countries. International Journal of Tuberculosis and Lung Disease, 2, 778-783.

[4] Shinnick, T.M. and Good, R.C. (1995) Diagnostic Mycobacteriology Laboratory Practices. Clinical Infectious Diseases, 21, 291-299. https://doi.org/10.1093/clinids/21.2.291

[5] Hanscheid, T. (2008) The Future Looks Bright: Low-Cost Fluorescent Microscopes for Detection of Mycobacterium Tuberculosis and Coccidiae. Transactions of the Royal Society of Tropical Medicine and Hygiene, 102, 520-521.

[6] Smithwick, R.W. (1976) Laboratory Manual for Acid-Fast Microscopy. 2nd Edition, US Public Health Service, Atlanta.

[7] Harries, A.D., Maher, D. and Nunn, P. (1998) An Approach to the Problems of Diagnosing and Treating Adult Smear-Negative Pulmonary Tuberculosis in HighHIV-Prevalence Settings in Sub-Saharan Africa. Bulletin of the World Health Organization, 76, 651-662.

[8] Kivihya-Ndugga, L.E., van Cleeff, M.R., Githui, W.A., Nganga, L.W., Kibuga, D.K., Odhiambo, J.A., et al. (2003) A Comprehensive Comparison of Ziehl-Neelsen and Fluorescence Microscopy for the Diagnosis of Tuberculosis in a Resource-Poor Urban Setting. International Journal of Tuberculosis and Lung Disease, 7, 1163-1171.

[9] Boyd, J.C. and Marr, J.J. (1975) Decreasing Reliability of Acid-Fast Smear Techniques for Detection of Tuberculosis. Annals of Internal Medicine, 82, 489-492. https://doi.org/10.7326/0003-4819-82-4-489

[10] Richards, O.W., Kline, E.K. and Leach, R.E. (1941) Demonstration of Tubercle Bacilli by Fluorescence Microscopy. The American Review of Tuberculosis, 44, 255

[11] Iseman, M.D. (2000) A Clinician's Guide to Tuberculosis. Lippincott, Williams and Wilkins, Philadelphia, 29.

[12] Kent, P.T. and Kubica, G.P. (1985) Public Health Mycobacteriology: A Guide for the Level III Laboratory. Centers for Disease Control, Atlanta.

[13] Ängeby, K.A., Hoffner, S.E. and Diwan, V.K. (2004) Should the "Bleach Microscopy Method" Be Recommended for Improved Case Detection of Tuberculosis? Litera- 
ture Review and Key Person Analysis. International Journal of Tuberculosis and Lung Disease, 8, 806-815.

[14] Government of India, Central TB Division (2005) Managing the Revised National Tuberculosis Control Programme in Your Area. Directorate General of Health Services. Ministry of Health and Family Welfare, New Delhi. http://www.tbcindia.nic.in/showfile.php?lid=2907

[15] Masood, Z., Mohammad, N., Majid, K. and Ghodsieh, A. (2008) Comparison of the Value of Two Different Sputum Staining for Diagnosis of Acid-Fast Bacilli. Iranian Journal of Clinical Infectious Diseases, 3, 99-102.

[16] Ba, F. and Rieder, H.L. (1999) A Comparison of Fluorescence Microscopy with the Ziehl-Neelsen Technique in the Examination of Sputum for Acid-Fast Bacilli. International Journal of Tuberculosis and Lung Disease, 3, 1101-1105.

[17] Trusov, A., Bumgarner, R., Valijev, R., Chestnova, R., Talevski, S., Vragoterova, C. and Neeley, E.S. (2009) Comparison of Lumin ${ }^{\mathrm{Tm}}$ LED Fluorescent Attachment, Fluorescent Microscopy and Ziehl-Neelsen for AFB Diagnosis. International Journal of Tuberculosis and Lung Disease, 13, 836-841.

[18] Weiser, O.L., Sproat, E.F., Hakes, J.D. and Morse, W.C. (1966) Fluorochrome Staining of Mycobacteria. Technical Bulletin of the Registry of Medical Technologists, 36, 257-258.

[19] Steingart, K.R., Henry, M., Vivienne, Ng., Hopewell, P.C., Ramsay, A., Cunningham, J., et al. (2006) Fluorescence versus Conventional Sputum Smear Microscopy for Tuberculosis: A Systematic Review. The Lancet Infectious Diseases, 6, 570-581.

Submit or recommend next manuscript to SCIRP and we will provide best service for you:

Accepting pre-submission inquiries through Email, Facebook, LinkedIn, Twitter, etc. A wide selection of journals (inclusive of 9 subjects, more than 200 journals) Providing 24-hour high-quality service User-friendly online submission system Fair and swift peer-review system Efficient typesetting and proofreading procedure Display of the result of downloads and visits, as well as the number of cited articles Maximum dissemination of your research work

Submit your manuscript at: http://papersubmission.scirp.org/

Or contact jtr@scirp.org 